\title{
Mapping the global flow of aluminium: from liquid aluminium to end-use goods
}

\begin{tabular}{|r|l|}
\hline Journal: & Environmental Science \& Technology \\
\hline Manuscript ID: & es-2012-04256s.R1 \\
\hline Manuscript Type: & Policy Analysis \\
\hline Date Submitted by the Author: & 30-Jan-2013 \\
\hline Complete List of Authors: & $\begin{array}{l}\text { Cullen, Jonathan; University of Cambridge, Engineering } \\
\text { Allwood, Julian; University of Cambridge, Engineering }\end{array}$ \\
\hline
\end{tabular}




\begin{abstract}
Demand for aluminium in final products has increased 30-fold since 1950 to 45 million tonnes per year, with forecasts predicting this exceptional growth to continue so that demand will reach 2 to 3 times today's levels by 2050 . Aluminium production uses $3.5 \%$ of global electricity and causes $1 \%$ of global $\mathrm{CO}_{2}$ emissions, while meeting a $50 \%$ cut in emissions by 2050 against growing demand would require at least a $75 \%$ reduction in $\mathrm{CO}_{2}$ emissions per tonne of aluminium produced-a challenging prospect. In this paper we trace the global flows of aluminium from liquid metal to final products, revealing for the first time a complete map of the aluminium system and providing a basis for future study of the emissions abatement potential of material efficiency. The resulting Sankey diagram also draws attention to two key issues. Firstly, around half of all liquid aluminium ( $\sim 39 \mathrm{Mt})$ produced each year never reaches a final product, and a detailed discussion of these high yield losses shows significant opportunities for improvement. Secondly, aluminium recycling, which avoids the high energy costs and emissions of electrolysis, requires signification 'dilution' ( $\sim 8 \mathrm{Mt})$ and 'cascade' $(\sim 6 \mathrm{Mt})$ flows of higher aluminium grades to make up for the shortfall in scrap supply and to obtain the desired alloy mix, increasing the energy required for recycling.
\end{abstract}




\section{Introduction}

Aluminium production is energy intensive and is a significant contributor to global greenhouse gas (GHG) emissions. Efforts to date have mainly been focused on decarbonising the energy supply, however providing sufficient 'clean' energy at scale and in time is proving to be very difficult. The International Energy Agency (IEA) in a recent report states that, "few clean energy technologies are currently on track" and that, "carbon capture and storage (CCS) is not seeing the necessary rates of investment". ${ }^{1}$ Slow progress is causing a shift in attention towards demand side measures. Yet, the processes used to make aluminium are already energy efficient, and demand is likely to double or treble over the next 40 years, so achieving an absolute reduction in emissions is still challenging and is likely to require the strategies of material efficiency. In order to plan our way towards a lower emissions aluminium future, we need to understand not just the processes, but also the flows of aluminium. A detailed map of global aluminium flows is needed to: understand the potential for future recycling which is complex due to the problems of balancing the alloy mix; forecast future emissions; evaluate the potential for energy and material efficiency options; ensure aluminium is used in the most effective applications where use-phase energy savings can be realised. However, existing maps lack sufficient detail to meet our needs, and therefore this paper seeks to create a new map of global flows.

\subsection{Demand for aluminium products}

Aluminium is the second most used metal after steel and more aluminium is produced than all other non-ferrous metals put together. End user demand for aluminium in final products has risen 30 -fold since 1950, reaching nearly 45Mt (million tonnes) in 2007 as shown in Figure $1{ }^{2-3}$ while meeting this demand required 11 kilograms of aluminium to be cast, every year, for every person on earth. Growth in demand is expected to continue, with the International Energy Agency (IEA) predicting that by 2050 demand for aluminium in final products will be between $110 \mathrm{Mt}$ and 153Mt.,4171 Orebased primary production continues to outpace production from recycled scrap, indicating that demand for new aluminium products rather than replacement products is driving growth, and unlike

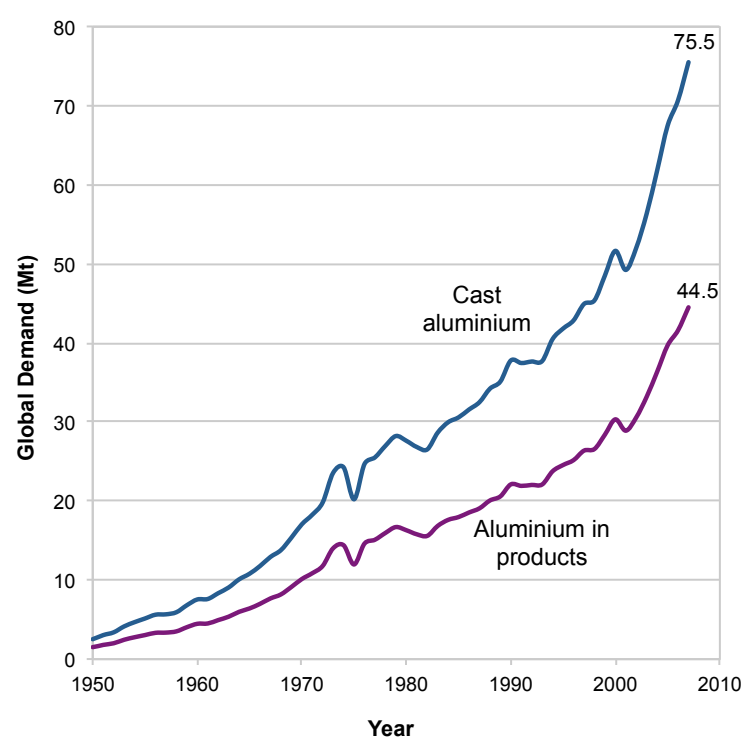

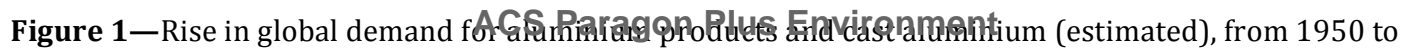
2007. 
steel, aluminium shows no sign of saturating at a constant stock level per person. ${ }^{5}$

Aluminium demand is estimated using production statistics, collated and published by numerous organisations, and representing different parts of the production supply chain and distinct geographical regions. Approximately 200 primary smelting plants operate around the world,, ,p. 6 in a highly consolidated industry, which aids the collection and accuracy of global primary production statistics. The International Aluminium Institute now represents $100 \%$ of global primary production and the U.S. Geological Survey (USGS) tracks global bauxite extraction, while regional data is collated by the European Aluminium Association (EAA) and The Aluminum Association, for North America.

In contrast, aluminium recycling occurs on a smaller industrial scale and consists of around 1200 remelter and refining plants ${ }^{6, p .6}$ supported by a network of collectors, dismantlers and scrap merchants operating at a local level. The collection of recycling data is therefore more difficult and less accurate. Despite these challenges the International Aluminium Institute (global), The Aluminum Association (North America) and the Organisation of the European Aluminium Recycling Industry (OEA) (Europe) all report aggregated recycling statistics for aluminium, which is complemented by national statistics offices, individual companies (e.g. Alcoa and Novelis) and media organisations (e.g. the CRU Group). Table S1 in the Supporting Information describes these data sources in more detail.

\subsection{Energy consumption and GHG emissions}

Ore-based 'primary' aluminium, made using the Hall-Héroult electrolysis process, is energy intensive and uses $3.5 \%$ of global electricity. 4 ,p161 Despite the high fraction of renewable electricity used for electrolysis, the aluminium industry still emits $0.4 \mathrm{GtCO}_{2}$ (about $1 \%$ of global energy and industrial process related GHG emissions) and the IEA baseline scenario predicts emissions will rise to between 1.0 and $1.4 \mathrm{GtCO}_{2}$ by $2050 .{ }^{4, p 161}$ At the same time, internationally agreed climate change targets, ${ }^{7}$ require a cut in total absolute emissions to less than half by 2050. If such targets were to be applied directly to the aluminium industry, in the face of a tripling in demand, then a challenging $85 \%$ reduction in emissions intensity (emissions per tonne of aluminium) would be needed.

More than $80 \%$ of the industry's $\mathrm{CO}_{2}$ emissions occur in the upstream aluminium production processes-bauxite mining, alumina refining, aluminium smelting, scrap melting and ingot castingand consequently most efforts to reduce emissions in the industry have been focused here. In a previous paper ${ }^{8}$ we assessed all known process efficiency options for reducing $\mathrm{CO}_{2}$ emissions from aluminium production in 2050 and found the reduction potential limited to only $23 \%$. The aluminium industry, being a heavy user of energy, has already exhausted most of the available process efficiency gains. Recycling scrap aluminium helps, as it requires less energy and generates fewer emissions than electrolysis, yet scrap availability lags well behind total aluminium demand preventing any significant shift away from primary production.

In response to the limited potential gains from process efficiency and scrap recycling, we have explored six material efficiency strategies ${ }^{9}$ which aim to reduce our demand for cast aluminium without compromising the service level provided by aluminium products: (i) using less metal by design; (ii) reducing yield losses; (iii) diverting manufacturing scrap; (iv) re-using metal components; (v) longer life products; (vi) reducing final demand. Initial results from our scenario work suggest that pursuing material efficiency strategies in addition to more conventional process efficiency 
options has the effect of doubling the overall emissions reduction potential. To further study the combined effects of process efficiency options and recycling potential, alongside our proposed material efficiency solutions, we require a detailed global map of aluminium which traces the physical flows of aluminium from liquid metal to final products.

\subsection{Limits of existing maps of aluminium flow}

The most significant contribution towards mapping aluminium flows comes from a combined industrial effort to create a global dynamic MFA model for aluminium flows and stocks. This original model was created at Alcoa in the late 1990s, then taken over by the Global Aluminium Recycling Committee (GARC), and is now being developed by the International Aluminium Institute. Bruggink and Martchek, ${ }^{10}$ Boin and Bertram (2005) ${ }^{11}$ and Martchek (2006) ${ }^{12}$ have published results from the model and describe its development during this time. The industry also recognized the benefits of reporting clear and transparent aluminium data, with the EAA publishing a 2004 Europe and global flow diagram based on the model ${ }^{13}$ and the International Aluminium Institute publishing an annual MFA diagram in their Aluminium for Future Generations reports (2006-2009), ${ }^{2}$ while also extending the regional coverage of the model.

This dynamic model of aluminium stocks and flows is built around annual primary aluminium production data and net product shipments by market sector, and for ten geographical regions. Scrap flows from casting, forming, and fabrication are estimated based on yield rates for each market sector, and end-of-life scrap from discarded products is estimated based on historical product shipments, product life times, scrap collection rates and melting yields. A full summary of the development of the dynamic MFA model is given by Bertram et al. ${ }^{14}$ and the International Aluminium Institute has recently created an online animated version of the flow diagram. ${ }^{15}$

Chen and Graedel ${ }^{16}$ provide a review of anthropogenic element cycles, listing 26 different material flow analysis (MFA) studies of aluminium across a range of geographical scales and life-cycle stages. Two additional sources were not included in the review, but proved useful for our analysis:

" Liu et al. (2011) $)^{5}$ create a dynamic material flow model to simulate aluminium stocks and flows in the U.S. and associated greenhouse gas emissions, and show that although in-use stocks are still growing large mitigation potential existing through recycling.

- AluNorf, the world's largest aluminium rolling and remelting plant, uses the European Commission's Eco-Management and Audit Scheme (EMAS) to report environment indicators for the operation of the plant. EMAS requires the company to disclose their annual material and energy flows, ${ }^{17}$ which they report using a material flow diagram.

Previous studies of aluminium flows are useful for discussion of issues in specific regions, processing routes and products. However, research to date is incomplete, and unsuitable for our purpose of assessing global emissions abatement options, because it is either not at the global scale, or in the case of the few global studies available, does not describe the entire supply chain in sufficient detail. This paper aims to provide a more detailed mapping of global aluminium flows and is motivated by three specific knowledge gaps in the existing MFA modelling literature:

- As aluminium flows from production (smelting and melting), through intermediate products, to final fabricated goods, the flows divide, becoming smaller and more diverse. A handful of flows 
might be sufficient to describe the upstream production of aluminium, whereas the downstream fabrication of aluminium products is more diverse and complex. For this reason, a detailed mapping of the links between intermediate products and fabricated goods is missing from the current MFA modelling, but is important if we wish to examine options for material efficiency.

- The global aluminium scrap system has to date only been mapped at an aggregated level, with no separation between the aluminium scrap flows to remelters (which melt scrap for use in wrought products) and to refiners (which melt scrap for use in cast products). Providing a detailed analysis of aluminium scrap flows is important as the value of recycling is undermined when alloy streams are mixed, down-cycled or diluted during melting.

- To create our map of global aluminium flows involves collating and balancing data from many different sources, giving us the opportunity to resolve discrepancies between existing data sets.

\section{Constructing a map of global aluminium flows}

In this section we describe the methodology for allocating aluminium flows and accounting for manufacturing yields using a matrix notation, and the population of the matrices using data from a range of sources, while ensuring a consistent mass balance. The resulting model of aluminium flows is presented visually as a Sankey diagram allowing comparisons to be quickly made between the scale of flows. The Sankey diagram format has been used previously by Cullen and Allwood to map global energy flows ${ }^{18-19}$ and to create an equivalent map of global steel flows. ${ }^{20} \mathrm{~A}$ preliminary version of the aluminium Sankey diagram was presented in the book, Sustainable Materials: with both eyes open. ${ }^{9, p 55}$ The map for this paper has been revised following further consultation with the International Aluminium Institute and our industrial partners, and cross-referencing to additional data sources. This resulted in substantial changes to many of aluminium flows, particularly for the scrap recycling flows to Remelters and Refiners, and required a complete rebalancing of the model. Furthermore, for the first time we have publish the detailed analysis and source data used to create the diagram in the comprehensive Supporting Information, enabling other research groups to use and build upon this work.

\subsection{Methodology}

The global aluminium supply chain is divided into five major process steps, shown in Table 1, which form the vertical slices of the Sankey diagram. Each slice can contain several individual processes, and represents a transformation of an input aluminium flow into three possible outputs: useful aluminium products; scrap aluminium; losses (typically as dross or oxidised aluminium).

\begin{tabular}{ll} 
Slices & Description \\
\hline $\begin{array}{l}\text { Electrolysis/ } \\
\text { Melting }\end{array}$ & $\begin{array}{l}\text { Alumina (extracted from bauxite ore) is converted using electrolysis to liquid aluminium ore. } \\
\text { Aluminium scrap (from forming, fabrication and end-of-life) is melted in remelters (to make } \\
\text { wrought alloys) and refiners (to make casting alloys). }\end{array}$ \\
Casting & $\begin{array}{l}\text { Liquid aluminium is cast into slab, billet and alloy ingots, and subsequent remelting and } \\
\text { casting in downstream facilities. }\end{array}$ \\
Rolling/ & $\begin{array}{l}\text { Slab ingots are hot rolled to plate and strip with some material undergoing further cold rolling } \\
\text { and foil rolling; billet ingots are extruded or wire drawn; alloy ingots are shape cast to produce } \\
\text { Shape Casting }\end{array}$ \\
a range of intermediate products.
\end{tabular}


Fabrication Intermediate products are cut, joined, machined and assembled into fabricated products.

End-uses $\quad$ Fabricated products are allocated to vehicles, industrial equipment, construction and metal products, and then divided further into subcategories.

Table 1-Major processes steps for aluminium are used to create the five vertical slices in the Sankey diagram.

For each of the five slices, we map the inputs (vector $\mathbf{x}$ ) onto the outputs (vector $\mathbf{y}$ ) using two matrices: an allocation matrix $\mathbf{A}$, which maps each input, by fractions, onto each output, and a manufacturing yield matrix $\mathbf{Y}$, which accounts for any material discarded as scrap in transforming the input materials into output products. The two matrices are of equal size and are multiplied element wise, using the Hadamard product (symbol $\circ$ ). Written formally:

$$
\mathbf{y}=(\mathbf{A} \circ \mathbf{Y}) \mathbf{x}
$$

An equivalent loss vector $\mathbf{y}_{L}$ is defined as:

$$
\mathbf{y}_{L}=(\mathbf{A} \circ(\mathbf{J}-\mathbf{Y})) \mathbf{x}
$$

where $\mathbf{J}$ is a matrix of ones, of equal size to $\mathbf{Y}$ and $\mathbf{A}$.

Four allocation matrices and four yield matrices are created to map the five slices in the Sankey diagram and populated using industrial statistics from a number of different sources. In some cases, the mapping is inferred, estimated or back calculated, if the direct values for the vectors or matrices are not available.

\subsection{Global model of aluminium flows}

In this section we summarise the main data sources, calculations and assumptions behind our global model. The model is balanced to remain consistent with the overview of major global aluminium flows in 2007, provided in the International Aluminium Institute's global mass flow diagram ${ }^{2}$ and supporting dynamic model. ${ }^{3}$ Full details of the data sources and the mapping process are given in the Supporting Information: $§ 2$.

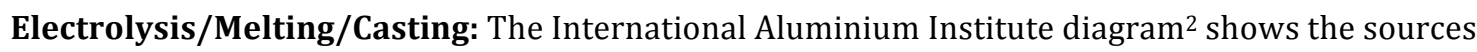
of liquid aluminium (75.6Mt) divided evenly into primary aluminium (electrolysis) and remelted aluminium (recycled scrap), while the International Aluminium Institute model ${ }^{3}$ gives a breakdown of the scrap inputs for remelting: casting (1.6Mt); internal scrap/forming (20Mt); fabrication (9.5Mt); post-consumer/end-of-life (8.3Mt).

Recycled aluminium is produced in two separate processes: Remelters, which produce wrought alloys ( $<10 \%$ alloy) for rolled and extruded products; Refiners, which produce casting alloys $(<20 \%$ alloy) for shape-cast products and deoxidation aluminium. Each scrap input flow is divided between the Remelter and the Refiner based on a mass balance of scrap flows for Europe, ${ }^{11}$ resulting in all casting scrap, $10 \%$ of wrought forming and fabrication scrap, and $78 \%$ of end-of-life scrap being sent to the Refiner.

The liquid aluminium from Electrolysis, Remelters and Refiners is cast into ingots for transportation to downstream production facilities, creating $1.6 \mathrm{Mt}^{3}$ of 'aluminium skimmings' of which $0.8 \mathrm{Mt}$ is 
recovered as aluminium. Internal casting losses (i.e. defects, sawing, scalping) are not reported by the International Aluminium Institute, but these remelting loops are estimated to add $9 \%$ to the cast output, using the Remelter mass balance from AluNorf. ${ }^{17}$ In many cases ingots are remelted and recast a second time to refine the alloy mix prior to downstream forming/casting processes, although fraction of recast aluminium could not be ascertained.

Scrap recycling requires the addition of primary aluminium to 'sweeten the melt' and obtain the desired alloy mix. The primary sweetner fraction for the Remelter is set at $5 \%$ based on a mass balance from AluNorf ${ }^{17}$ and the observed fraction at a UK remelting facility producing UBC ingots. The sweetner fraction for the Refiner is found by balancing the demand for wrought alloys (46.7Mt) and shape-casting alloys (27.3Mt) against the scrap inputs to the Remelter (16.9Mt) and the Refiner (22.4Mt), after accounting for casting yield losses. ${ }^{3}$ The result is $7.1 \mathrm{Mt}$ of primary sweetner input to the Refiner, equal to $25 \%$ of the Refiner input.

Rolling/Forming/Shape Casting: The demand for Rolling, Extrusion, Wire Drawing and Shape Casting is back calculated from the Intermediate Product vector. The International Aluminium Institute model ${ }^{4}$ lists semi-fabricator yields (corresponding to our forming/casting processes), but these are organized by end-use categories. It is more accurate to estimate the forming/casting yields directly for each process while accounting for the cascading flows between the hot, twin roll, cold and foil rolling processes. Therefore, we survey forming yields from four literature sources-AluNorf,17 EAA, ${ }^{21}$ Milford et al.,22 Schifo and Radia ${ }^{23}$ - covering individual processes and multi-process chains, to assign yields to each forming/casting process. These are adjusted in combination with the Forming/Casting allocation matrix to match the total forming/casting scrap of 20Mt from the International Aluminium Institute global diagram. ${ }^{2}$

Fabrication: The International Aluminium Institute model ${ }^{3}$ collates net product shipments (equivalent to Intermediate Products in our model) for the ten major regions covering the world (1950-2007) and estimates fabrication yields to generate a breakdown of "finished products", which are matched to the End-use categories in our model. However, the International Aluminium Institute product shipment data is organised by end-uses (i.e. buildings, transport, machinery) rather than intermediate product categories (i.e. rolled, extruded, shape-cast) required for the Sankey diagram. Therefore, we back-calculate the Intermediate Product vector by using the fabrication yields from the International Aluminium Institute model and creating a fabrication allocation matrix: using sector specific breakdowns from North America ${ }^{24, t a b 13}$ for Construction and Transport end-uses; assuming Mechanical Equipment has a similar breakdown to Cars; using direct one-to-one allocations for Electrical Cable and Drinks Cans; estimating breakdowns for Other Electrical and the remaining Metals Products. Each row of the matrix is finally balanced to match the End-uses vector, while the total fabrication scrap is constrained to match the International Aluminium Institute value of $9.5 \mathrm{Mt}^{2}$ A complete description of the data sources and assumptions is provided in the Supporting Information, $\$ 2.7$.

\subsection{Data uncertainty}

Aluminium production statistics are not reported with error bands, as is common for experimental findings, making it impossible to determine data accuracy or perform an uncertainty analysis for our model. Data is normally collated from individual company surveys, which are aggregated at the 
country, regional or global level and reported in national statistical bodies and by trade organisations. Some likely sources of uncertainty are: misinterpretation of the survey questions and the terminology used to describe process and materials; unintentional or deliberate misreporting of data in the surveys; incomplete coverage of global production facilities, requiring data to be scaled; calculation errors in the aggregation of data; miscommunication of data in published reports. Organisations such as the International Aluminium Institute work to minimise data errors, by crossreferencing data sources and auditing their data collection practices, nevertheless some degree of error is still likely to persist.

In our analysis, we attempt to further minimise data uncertainty by: relying heavily on a few trusted sources, which are then validated against other sources when available; using mass balance checks for every process and slice to ensure mass conservation; publishing a full supporting information that describes in detail the sources and calculations used in our model. Aluminium flows are reported in the paper to the nearest 100,000 tonnes of aluminium as a precaution to avoid any overstatement of the data accuracy. Despite the limitations of using data of unknown accuracy, our whole-system approach is still valid for comparing the relative scale of global aluminium flows and for directing actions towards where the largest gains can be made.

\section{Results}

Figure 2 presents a map of global aluminium flow for 2007, which traces the flow of aluminium from aluminium production (left) through to fabricated products (right). The map is drawn in a Sankey diagram format, such that the width of each horizontal line in the map is proportional to the mass flow of aluminium, with specific flows given in million tonnes (Mt). A vertical black line indicates a major process step in the aluminium supply chain, where the aluminium flow is split into three possible outputs: useful metal (shown in colour); losses, typically dross or aluminium oxide (shown black); and process scrap which loops back to a melting step for recycling (shown in grey). Two 'recasting' processes are shown with dashed vertical black lines to indicate that some aluminium ingots are remelted and cast a second time to adjust the alloy concentrations or to create an ingot shape more suitable for the downstream processes, although the fraction of aluminium that is recast is unknown. 
The map is the first breakdown of global scrap flows through Remelters and Refiners, including calculation of the dilution flows of primary aluminium to the remelting processes. It is also the first study to map intermediate products onto end-use goods in detail and to disaggregate the scrap generation from rolling, extrusion and shape-casting processes.

\section{Electrolysis / Melting}

Casting Rolling / Forming / Casting

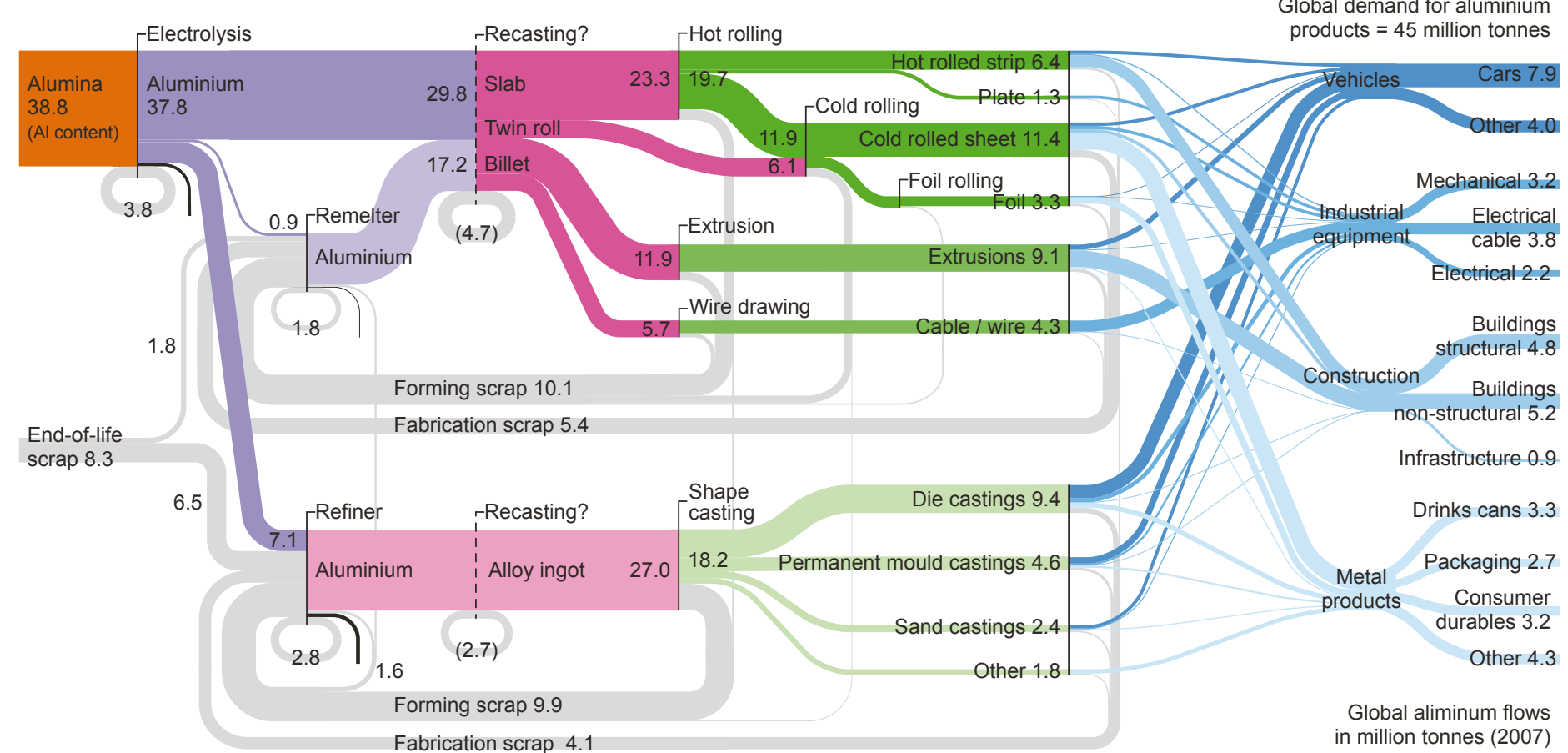

Figure 2-Sankey diagram, tracing the global flow of aluminium from ore-based and scrap-based production, through casting, forming and fabrication processes, to deliver end-use goods.

\section{Discussion}

Figure 2 shows the relative scale of different aluminium flows in the supply chain. For example, a quick scan of the map shows: roughly half of all aluminium is made from bauxite ore and half from recycled scrap; two-thirds of cast aluminium is formed into wrought products and one-third shapecast; final product demand is divided roughly evenly between vehicles, industrial equipment, construction and metal products. Two additional aspects of the global aluminium map demand further attention: (i) the poor material efficiency of the industry, where approximately $50 \%$ of all cast aluminium is discarded as scrap during manufacturing; (ii) the significant 'dilution' and 'cascade' flows from high grade aluminium to lower purity alloys and the effect on the energy required for recycling. 


\subsection{Material efficiency and industrial scrap}

The material efficiency of the aluminium production system is surprisingly low in comparison to other engineering materials. From a reported $74 \mathrm{Mt}$ of cast aluminium, ${ }^{2}$ the industry delivers only 44.5Mt of final products to consumers-at an average material efficiency (manufacturing yield) of $60 \%$ - with the remaining aluminium discarded as industrial scrap during manufacturing. If we include the unreported internal recycling of casting scrap, the material efficiency falls to $53 \%$ with almost half of all cast aluminium (39.4Mt) discarded as industrial scrap. Furthermore, if we assume that $70 \%$ of all ingots are recast, then the fraction of industrial scrap rises to $50 \%$ of all cast aluminium. In comparison, steel production has an average material efficiency of $76 \% .{ }^{20}$ (Full calculations are included in the Supporting Information, Table S7.)

Certainly, every effort should be made to collect and recycle aluminium scrap, whether the source is manufacturing processes or consumer discards. Current collection efficiencies for industrial scrap are high, so efforts should be focused on end-of-life recycling where collection rates are estimated to range from $50 \%$ in some sectors to as high as $90 \%$ for construction and transport. ${ }^{3}$ (In comparison, steel recycling is reported to average $80 \%,{ }^{25}$ although the exact calculation method may differ.) Yet, of even more importance than recycling is avoiding the generation of scrap at source, through improvements to manufacturing processes, so that recycling of industrial scrap is no longer required.

Analysing the material yields across ingot casting, forming and fabrication processes reveals the reasons behind the high losses of industrial scrap and points to technical options for improving material efficiency.

Ingot casting: The material yield for aluminium ingot casting is $88 \%$ (including internally recycled scrap), much lower than the equivalent for steel of $94 \% .{ }^{20}$ The difference is mainly due to the need to remove inferior quality surface material from ingots (by scalping and sawing) and defects created in the batch casting process, and because the greater material losses can be offset against the typically higher value of aluminium products. The resulting scrap is recycled internally but often not reported in company and industry statistics, and although the overall metal balance is unaffected, the remelting of scrap consumes additional energy.

Almost all aluminium is as some point cast as an ingot, so any improvement in the casting yield has the potential to deliver savings across all products. Electromagnetic casting (EMC) is an alternative ingot casting technology which avoids any contact with a physical mould during casting, providing a smooth cast surface that can normally be rolled without scalping. ${ }^{26}$ Introducing intensive shearing during the melting of aluminium disperses porosity in the melt resulting in considerable reductions in cast defects. ${ }^{27}$ Application of these technologies would increase the material yield of ingot casting from $88 \%$ to an estimated $92 \%$.

Rolling/Forming/Shape-Casting: The overall material efficiency of rolling, forming and shapecasting is $73 \%$, which is well below the yield for steel at $92 \%,{ }^{20}$ with three reasons suggested for the difference. Firstly, a third of all aluminium products are shape-cast compared with only $6 \%$ for steel, and product casting has comparatively lower yields (67\%) than other forming processes $(77 \%$ for aluminium and $90 \%-96 \%$ for steel) due to the complex set of 'runner', 'riser' and 'gating' systems which feed liquid metal into the casting mould. Secondly, one quarter of aluminium products are 
extruded at a comparably low material yield of $76 \%$, whereas extruded steel products are much less common. Thirdly, the average material yield for rolling aluminium is only $75 \%$, compared to $92 \%$ for steel rolling, which can be explained by: the sawing and scalping of slab ingots prior to hot rolling; aluminium being softer than steel and more prone to damage while handling; aluminium being rolled to finer grades and higher surface finishes than steel, resulting in a more quality control defects.

Two key yield improvements are described below, which if implemented would raise the overall material efficiency for forming processes from $73 \%$ to $82 \%$. Firstly, Schifo and Radia ${ }^{23}$ estimate that a $5 \%$ gain in yield can be achieved for aluminium shape-casting, citing improvements to computer solidification modelling and research into the "application of acoustic energy to reduce gating weight and improve casting quality". We assume a similar 5\% improvement is achievable in extrusion and wire drawing processes. Secondly, continuous casting processes, such as twin-roll casting, produce a cast 'sheet' which can be immediately cold-rolled without the need for ingot casting, scalping/sawing and hot rolling. The technology is particularly suited for non-heat treatable alloys and currently onethird of all cold-rolled sheet and foil can be continuously cast. ${ }^{28}$ To calculate the potential savings in industrial scrap, we assume that all cold-rolled sheet and foil is continuously cast, which is equal to two-thirds of all rolled products, noting that $90 \%$ of rolled products are made from non-heat treatable alloys. ${ }^{24}$

Fabrication: The yield for aluminium fabrication processes is $82 \%$, which is only slightly lower than the yield for steel at $85 \%,{ }^{20}$ and is probably due to aluminium components being typically smaller and more complex than steel products. Reducing industrial scrap across all processes is made more difficult by the lower melting temperature of aluminium, at $600^{\circ} \mathrm{C}$ compared to $1600^{\circ} \mathrm{C}$ for steel, which results in lower energy costs for remelting, creating less incentive to reduce aluminium manufacturing scrap. Based on a previous analysis, ${ }^{8}$ we estimate that fabrication yields could be increased up to $90 \%$.

Potential to reduce industrial scrap: The technical options and estimated yield improvements described above represent our best estimate of the practical limits of material efficiency applied to industrial aluminium scrap. We calculate that if all options were applied together, then today's 45Mt of aluminium in end-use goods would require only 65Mt of cast aluminium, avoiding 19Mt of industrial scrap recycling. In practice, a detailed analysis of the economic and institutional barriers would be required to assess the likely adoption of this material efficiency strategy.

\subsection{Is recycling always the best option?}

Recycling is less energy intensive than making aluminium from ore, but recycling is not always as good as it looks. In particular, the practice of dilution and cascading result in significant flows of aluminium from high-grade to lower purity alloys, increasing the energy required for recycling.

Dilution: Our map of global aluminium flows (Figure 2) shows 8.0Mt per year of pure aluminium being used to dilute (or 'sweeten') the alloy mixes in the Remelting and Refining processes.

Thermodynamics dictates that it is easy to add alloys to aluminium but very difficult to remove them, and therefore dilution is mostly irreversible and results in a permanent downgrading of aluminium quality. The practice of dilution also distorts the energy requirement of recycling. 
Table 2 demonstrates that the embodied energy of recycled aluminium increases rapidly when using primary 'sweetner' to dilute the alloy mix. The baseline energy requirements are taken directly from the International Aluminium Institute recycling website, ${ }^{15}$ and matches the claim that "Aluminum recycling requires up to $95 \%$ less energy than primary production" if a direct comparison is made between electrolysis against scrap melting. However, diluting the scrap mix with 5\% pure aluminium sweetner (e.g. as calculated for Remelters) nearly doubles the embodied energy of the recycled aluminium, and the addition of $25 \%$ sweetner (as observed for Refiners) results in a five-fold increase in embodied energy, with aluminium recycling now requiring nearly one-third of the energy of primary production. Furthermore, the collection, sorting and cleaning of recycled scrap, and manufacturing the product for a second time, add even more energy to the equation.

\begin{tabular}{lrrrr}
$\begin{array}{l}\text { Pure Al used } \\
\text { to dilute } \\
\text { scrap (\%) }\end{array}$ & $\begin{array}{r}\text { Recycling } \\
(\mathrm{GJ} / \mathrm{t})^{\mathrm{a}}\end{array}$ & $\begin{array}{r}\text { Electrolysis } \\
(\mathrm{GJ} / \mathrm{t}) \mathrm{b}\end{array}$ & $\begin{array}{r}\text { Total } \\
(\mathrm{GJ} / \mathrm{t})\end{array}$ & $\begin{array}{r}\text { Compared to } \\
\text { electrolysis (\%) }\end{array}$ \\
\cline { 2 - 5 } Electrolysis (pure Al) & 0 & 170 & 170 & $100 \%$ \\
Industry claim (0\%) & 10 & 0 & 10 & $6 \%$ \\
Remelter (5\%) & 10 & 9 & 19 & $11 \%$ \\
Refiner (25\%) & 10 & 43 & 53 & $31 \%$ \\
\hline
\end{tabular}

Notes:

a It is assumed that the pure $\mathrm{Al}$ from electrolysis (sweetner) must be remelted using the same energy as required for melting scrap

b Energy embodied in the primary 'sweetner' during primary production of aluminium using electrolysis.

Table 2-The effect of using pure aluminium (sweetner) to dilute scrap , on the embodied energy of recycled aluminium.

The global mass balance requires a dilution flow of pure aluminium to meet the demand for shape cast products, resulting in an average $25 \%$ sweetner fraction for Refiners. The only feasible alternative to balance scrap supply with cast product demand would be a significant increase in the down-cycling of wrought industrial scrap to the Refiner. Such a scenario would contradict the mass balance data from Europe, and would still result in the down-grading of higher quality aluminium and increase the embodied energy of recycled aluminium. The high fraction of pure aluminium sweetner used in Refiners is surprising. It indicates the level of scrap supply constraint that Refiners are forced to operate under, for without the use of pure aluminium, Refiners would be unable to realise the residual value of the recycled scrap.

Down-cycling: Six main alloying metals-copper, magnesium, manganese, silicon, zinc and lithiumare added to wrought alloys in low concentrations and casting alloys in higher concentrations. Nakajima et al. have evaluated the removal limits of alloys and impurities during aluminium scrap melting and concluded that apart from magnesium and zinc, all other alloying elements are almost impossible to remove, even under varying temperature and oxygen partial pressure conditions. ${ }^{29}$ For this reason, wrought alloys can be recycled into casting alloys, but the reverse is practically impossible, so recycling tends to cascade or down-cycle from wrought alloys to less pure shape casting alloys. 
Figure 2 shows the extent of down-cycling in the aluminium industry, which results in an estimated 6.1Mt of wrought scrap being diverted into cast products:

- Only about a fifth of end-of-life scrap is remelted into wrought alloys, despite wrought products outweighing cast production by two to one. We estimate that 3.7Mt of wrought scrap is downcycled into cast products, assuming product lifetimes for wrought and cast products are the same.

- Industrial scrap can be easily segregated and cleaned, yet we found that $10 \%$ of industrial scrap from forming and fabrication processes (1.7Mt) is still diverted to refiners to make casting alloys.

- Wrought ingot casting losses (skimmings, $0.7 \mathrm{Mt}$ ) are sent for reprocessing to remove impurities, but the recovered aluminium is not returned to Remelters, but instead is cascaded to Refiners.

The recycling system in its current form is only viable because growth in demand for new products outstrips the scrap aluminium available from discarded products, allowing wrought scrap to be downgraded and used in cast products, while primary aluminium is mainly used in wrought products. This behaviour is rational given the current economic drivers in the system, where the scrap supply will cascade to the whomever values the material, irrespective of what is the most optimal solution for material efficiency. However, in future, the recycling path for scrap from cast products may become constrained. Modaresi and Müller ${ }^{30}$ have explored such a scenario for automobiles and show that under business as usual assumptions a surplus of non-recyclable casting scrap will emerge by $2018 \pm 5$ years, while Hatayama et al. ${ }^{31}$ forecast a surplus of $6.1 \mathrm{Mt}$ of unrecyclable scrap in 2030, for Europe, United States, Japan and China, due to decreasing demand for cast alloys resulting from the introduction of electric vehicles. Such projections require a dynamic analysis of aluminium stocks over many years, as the supply and price of recycled aluminium depends critically on the flow of stock products reaching end-of-life, as explained by Blomberg and Soderholm. ${ }^{32}$

Options to minimise dilution and down-cycling: We have identified four possible solutions for addressing the problems of dilution and down-cycling, which will require further research and development to be realised:

- Develop better solutions for segregating and sorting of end-of-life scrap, and promote take-back loyalty schemes for unwanted products, to raise the fraction of wrought aluminium recycled in Remelters. Limiting the number of different alloys in today's products would aid the future separation and recovery of specific alloys.

- Explore options to reuse discarded products, to avoid recycling completely.

- Reduce any potential surplus of casting alloys by developing new shape-cast product applications. Research at the Brunel Centre for Advanced Solidification Technology on grain refinement of as-cast aluminium alloys using physical shear of the alloy melt and enhanced heterogeneous nucleation, is expected to deliver improved mechanical properties for cast products without the need for forming and heat treatment processes. ${ }^{27}$ 
- Develop a better understanding of the demand drivers for cast and wrought products and the future availability of scrap, so future shortfalls or surpluses of specific alloys can be identified and responses formulated to avoid the practice of diluting scrap with pure aluminium.

\subsection{Future work}

In this paper, we have mapped the flow of aluminium from liquid aluminium to final products for the year 2007 and developed a framework for directing actions to improve material efficiency and reduce the environmental impacts of aluminium production. We have identified a genuine need to improve data collection for Remelting and Refining processes, and in particular to ascertain the fraction of aluminium ingots which are recast before forming processes and to confirm the fraction of pure aluminium sweetner used for dilution of the alloy mix.

In future work, it would be possible to include the energy inputs and resulting $\mathrm{CO}_{2}$ emissions in the model, and use dynamic modelling and demand scenarios to predict how the map might change in the future, along with an economic analysis to compare the costs of different strategies. Finally, further work is required to evaluate the impact of economic and institutional barriers on the group of strategies described by material efficiency. 


\section{Acknowledgements}

Both the authors are supported by a Leadership Fellowship provided by the UK Engineering and Physical Sciences Research Council (EPSRC) reference EP/G007217/1. The authors would like to thank Margarita D. Bambach, Daniel R. Cooper, Rachel L. Waugh and Chris Bayliss for their generous contributions to the paper.

\section{Supporting Information Available}

The Supporting Information for this paper describes in detail the assumptions, calculations, and references used to construct the map of global aluminium flows. This material is available free of charge via the Internet at http://pubs.acs.org.

\section{References}

1. Tracking Clean Energy Progress: Energy Technology Perspectives 2012 excerpt as IEA input to the Clean Energy; International Energy Agency, OECD, Paris, France 2012; http://www.iea.org/media/etp/Tracking_Clean_Energy_Progress.pdf/

2. Aluminium for future generations/2008 update; International Aluminium Association: London, 2008; http://www.world-aluminium.org/media/filer/2012/06/12/fl0000286.pdf/

3. Global Aluminium Recycling Committee mass flow model; International Aluminium Association: London, 2011.

4. Energy technology transitions for industry 2009: strategies for the next industrial revolution; International Energy Agency: Paris, 2009; http://www.iea.org/textbase/nppdf/free/2009/industry2009.pdf/

5. Liu, G.; Bangs, C.E; Müller, D.B. Unearthing potentials for decarbonizing the U.S. aluminum cycle. Environ. Sci. Technol. 2011, 45 (22), 9515-22.

6. Luo, Z.; Soria, A. Prospective study of the world aluminium industry; Joint Research Centre, Institute for Prospective Technological Studies, European Communities: Luxembourg, 2008; http://ftp.jrc.es/EURdoc/JR40221.pdf/

7. G8 Hokkaido Toyako summit leaders declaration; Ministry of Foreign Affairs of Japan, July 8, 2008; http://www.mofa.go.jp/policy/economy/summit/2008/doc/doc080714_en.html/

8. Allwood, J. M.; Cullen, J. M.; Milford, R. L. Options for achieving a 50\% cut in industrial carbon emissions by 2050. Environ. Sci. Technol. 2010, 44 (6), 1888-94.

9. Allwood, J. M.; Cullen J. M.; Carruth M. A.; Cooper D. R.; McBrien M.; Milford R. L.; Moynihan M.; Patel A.C.H. Sustainable materials: with both eyes open. UIT: Cambridge, England, 2012; http://www.withbotheyesopen.com/

10. Bruggink, P. R; Martchek, K. J. World-wide recycled aluminum supply and environmental impact model. In, Light Metals and Metal Matrix Composites 2004: Hamilton, Ontario, Canada, 22-25 August 2004.

11. Boin, U.M.J.; Bertram, M. Melting standardized aluminum scrap: A mass balance model for Europe. JOM 2005, 57(8), 26-33.

12. Martchek, K.J. Modelling more sustainable aluminium. Int J LCA 2006, 11(1), pp.34-37. 
13. Global aluminium recycling: a cornerstone of sustainable development; European Aluminium Association: Brussels; International Aluminium Association: London; Organisation of European Aluminium Refiners and Remelters: Dusseldorf, Germany; 2009.

14. Bertram, M.; Martchek, K.J.; Rombach, G. Material flow analysis in the aluminum industry. J Ind Ecol. 2009, 13(5), 650-654.

15. Recycling website; International Aluminium Association: London, 2012, http://recycling.worldaluminium.org/

16. Chen, W.Q.; Graedel, T.E. Anthropogenic cycles of the elements: a critical review. Environ. Sci. Technol. 2012, 46 (16), 8574-86.

17. Environmental Statement 2010. Aluminium Norf GMbH (AluNorf): Neuss, Germany, 2010, http://www.alunorf.com/english/sicherheit_umwelterklaerung.php/

18. Cullen, J. M.; Allwood, J. M. The efficient use of energy: tracing the global flow of energy from fuel to service. Energy Policy 2010, 38 (1), 75-81.

19. Cullen, J. M.; Allwood, J. M. Theoretical efficiency limits for energy conversion devices. Energy 2010, 35 (5), 2059-69.

20. Cullen, J.M.; Allwood J.M.; Bambach M.D. Mapping the global flow of steel: from steelmaking to end-use goods. Environ. Sci. Technol. 2012, 46 (24), 13048-55.

21. Environmental profile report for the European aluminium industry. European Aluminium Association: Brussels; Organisation of the European Aluminium Recycling Industry: Dusseldof, Germany; 2008. http://www.alueurope.eu/environmental-profile-report/

22. Milford, R. L.; Allwood, J. M.; Cullen, J.M. Assessing the potential of yield improvements, through process scrap reduction, for energy and $\mathrm{CO}_{2}$ abatement in the steel and aluminium sectors. Resour. Conserv. Recy. 2011, 55 (12), 1185-95.

23. Schifo J.F. and Radia J.T. Theoretical/best practice energy use in metalcasting operations; U.S. Department of Energy Industrial Technologies Program: Washington, DC, 2004. http://prod.afsinc.rd.net/files/best\%20practice\%20energy-schifo-radia-may\%202004.pdf/

24. Aluminum Statistical Review for 2008; The Aluminum Association: Arlington, VA, 2008.

25. Fact sheet: steel and raw materials; World Steel Association: Brussels, 2011; http://www.worldsteel.org/dms/internetDocumentList/fact-sheets/Fact-sheet_Rawmaterials2011/document/Fact\%20sheet_Raw\%20materials2011.pdf/

26. Prasso, D.C.; Evans, J.W.; Wilson, I.J. Heat Transport and Solidifcation in the Electromagnetic Casting of Aluminium Alloys: Part I. Experimental Measurements on a Pilot Scale Caster. Metall. Trans B., 1995(26B), $1243-1251$

27. Fan, Z.; Wang, Y.; Xia, M.; Arumuganathar S. Enhanced heterogeneous nucleation in AZ91D alloy by intensive melt shearing, Acta Materialia 2009, 57(16) 2009, 4891-4901.

28. Hamer, S.; Romanowski, C.; Taraglio, B. Continuous casting and rolling of aluminum: Analysis of capacities, products ranges and Technology, Light Metal Age 2002, 60, 6-17.

29. Nakajima, K.; Takeda O.; Miki, T.; Matsubae, K.; Nakamura, S.; Nagasaka, T. Thermodynamic analysis of contamination by alloying elements in aluminum recycling. Environ. Sci. Technol. 2010. 44(14), 5594-6000

30. Modaresi, R.; Müller, D.B. The role of automobiles for the future of aluminium recycling. Environ. Sci. Tech. 2012(46), 8587-94. 
31. Hatayama, H.; Daigo, I.; Matsuno, Y.; Adachi, Y. Evolution of aluminum recycling initiated by the introduction of next-generation vehicles and scrap sorting technology. Resour. Conserv. Recy. 2012, 66 (12) 8-14.

32. Blomberg, J.; Soderholm, P. The economics of secondary aluminium supply: an econometric analysis based on European data. Resour. Conserv. Recy. 2009, 53 (8) 455-463. 
Mapping the global flow of aluminium:

from liquid aluminium to end-use goods

\author{
Jonathan M. Cullena* \\ Julian M. Allwooda \\ * corresponding author \\ a Department of Engineering \\ University of Cambridge \\ Trumpington Street \\ Cambridge, CB21PZ \\ United Kingdom \\ Tel: +44 1223760360 \\ Fax: +44 1223332643 \\ Email: jmc99@cam.ac.uk
}

\begin{abstract}
Demand for aluminium in final products has increased 30-fold since 1950 to 45 million tonnes per year, with forecasts predicting this exceptional growth to continue so that demand will reach 2 to 3 times today's levels by 2050 . Aluminium production uses $3.5 \%$ of global electricity and causes $1 \%$ of global $\mathrm{CO}_{2}$ emissions, while meeting a $50 \%$ cut in emissions by 2050 against growing demand would require at least a $75 \%$ reduction in $\mathrm{CO}_{2}$ emissions per tonne of aluminium produced-a challenging prospect. In this paper we trace the global flows of aluminium from liquid metal to final products, revealing for the first time a complete map of the aluminium system and providing a basis for future study of the emissions abatement potential of material efficiency. The resulting Sankey diagram also draws attention to two key issues. Firstly, around half of all liquid aluminium ( $39 \mathrm{Mt})$ produced each year never reaches a final product, and a detailed discussion of these high yield losses shows significant opportunities for improvement. Secondly, aluminium recycling, which avoids the high energy costs and emissions of electrolysis, requires signification 'dilution' ( $\sim \mathrm{Mt})$ and 'cascade' ( $\sim 6 \mathrm{Mt}$ ) flows of higher aluminium grades to make up for the shortfall in scrap supply and to obtain the desired alloy mix, increasing the energy required for recycling.
\end{abstract}




\section{Introduction}

Aluminium production is energy intensive and is a significant contributor to global greenhouse gas (GHG) emissions. Efforts to date have mainly been focused on decarbonising the energy supply, however providing sufficient 'clean' energy at scale and in time is proving to be very difficult. The International Energy Agency (IEA) in a recent report states that, "few clean energy technologies are currently on track" and that, "carbon capture and storage (CCS) is not seeing the necessary rates of investment". ${ }^{1}$ Slow progress is causing a shift in attention towards demand side measures. Yet, the processes used to make aluminium are already energy efficient, and demand is likely to double or treble over the next 40 years, so achieving an absolute reduction in emissions is still challenging and is likely to require the strategies of material efficiency. In order to plan our way towards a lower emissions aluminium future, we need to understand not just the processes, but also the flows of aluminium. A detailed map of global aluminium flows is needed to: understand the potential for future recycling which is complex due to the problems of balancing the alloy mix; forecast future emissions; evaluate the potential for energy and material efficiency options; ensure aluminium is used in the most effective applications where use-phase energy savings can be realised. However, existing maps lack sufficient detail to meet our needs, and therefore this paper seeks to create a new map of global flows.

\subsection{Demand for aluminium products}

Aluminium is the second most used metal after steel and more aluminium is produced than all other non-ferrous metals put together. End user demand for aluminium in final products has risen 30 -fold since 1950, reaching nearly 45Mt (million tonnes) in 2007 as shown in Figure $1{ }^{2-3}$ while meeting this demand required 11 kilograms of aluminium to be cast, every year, for every person on earth. Growth in demand is expected to continue, with the International Energy Agency (IEA) predicting that by 2050 demand for aluminium in final products will be between $110 \mathrm{Mt}$ and 153Mt.,4171 Orebased primary production continues to outpace production from recycled scrap, indicating that demand for new aluminium products rather than replacement products is driving growth, and unlike

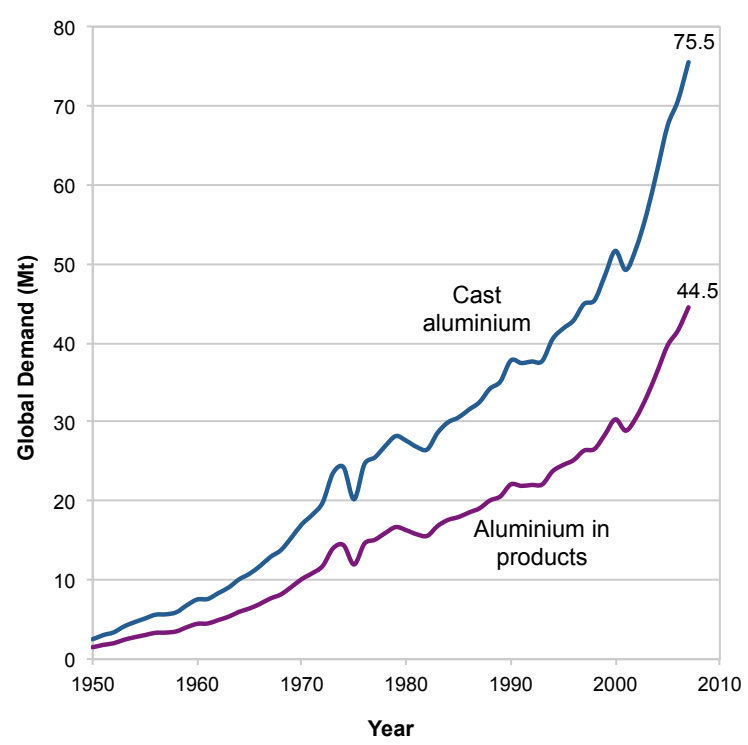

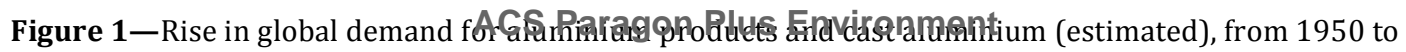
2007. 
steel, aluminium shows no sign of saturating at a constant stock level per person. ${ }^{5}$

\begin{abstract}
Aluminium demand is estimated using production statistics, collated and published by numerous organisations, and representing different parts of the production supply chain and distinct geographical regions. Approximately 200 primary smelting plants operate around the world,, ,p. 6 in a highly consolidated industry, which aids the collection and accuracy of global primary production statistics. The International Aluminium Institute now represents $100 \%$ of global primary production and the U.S. Geological Survey (USGS) tracks global bauxite extraction, while regional data is collated by the European Aluminium Association (EAA) and The Aluminum Association, for North America.

In contrast, aluminium recycling occurs on a smaller industrial scale and consists of around 1200 remelter and refining plants ${ }^{6, p .6}$ supported by a network of collectors, dismantlers and scrap merchants operating at a local level. The collection of recycling data is therefore more difficult and less accurate. Despite these challenges the International Aluminium Institute (global), The Aluminum Association (North America) and the Organisation of the European Aluminium Recycling Industry (OEA) (Europe) all report aggregated recycling statistics for aluminium, which is complemented by national statistics offices, individual companies (e.g. Alcoa and Novelis) and media organisations (e.g. the CRU Group). Table S1 in the Supporting Information describes these data sources in more detail.
\end{abstract}

\title{
1.2 Energy consumption and GHG emissions
}

Ore-based 'primary' aluminium, made using the Hall-Héroult electrolysis process, is energy intensive and uses $3.5 \%$ of global electricity.,p161 Despite the high fraction of renewable electricity used for electrolysis, the aluminium industry still emits $0.4 \mathrm{GtCO}_{2}$ (about $1 \%$ of global energy and industrial process related GHG emissions) and the IEA baseline scenario predicts emissions will rise to between 1.0 and $1.4 \mathrm{GtCO}_{2}$ by $2050 .{ }^{4, p 161}$ At the same time, internationally agreed climate change targets, ${ }^{7}$ require a cut in total absolute emissions to less than half by 2050. If such targets were to be applied directly to the aluminium industry, in the face of a tripling in demand, then a challenging $85 \%$ reduction in emissions intensity (emissions per tonne of aluminium) would be needed.

More than $80 \%$ of the industry's $\mathrm{CO}_{2}$ emissions occur in the upstream aluminium production processes-bauxite mining, alumina refining, aluminium smelting, scrap melting and ingot castingand consequently most efforts to reduce emissions in the industry have been focused here. In a previous paper ${ }^{8}$ we assessed all known process efficiency options for reducing $\mathrm{CO}_{2}$ emissions from aluminium production in 2050 and found the reduction potential limited to only $23 \%$. The aluminium industry, being a heavy user of energy, has already exhausted most of the available process efficiency gains. Recycling scrap aluminium helps, as it requires less energy and generates fewer emissions than electrolysis, yet scrap availability lags well behind total aluminium demand preventing any significant shift away from primary production.

In response to the limited potential gains from process efficiency and scrap recycling, we have explored six material efficiency strategies ${ }^{9}$ which aim to reduce our demand for cast aluminium without compromising the service level provided by aluminium products: (i) using less metal by design; (ii) reducing yield losses; (iii) diverting manufacturing scrap; (iv) re-using metal components; (v) longer life products; (vi) reducing final demand. Initial results from our scenario work suggest 
that pursuing material efficiency strategies in addition to more conventional process efficiency options has the effect of doubling the overall emissions reduction potential. To further study the combined effects of process efficiency options and recycling potential, alongside our proposed material efficiency solutions, we require a detailed global map of aluminium which traces the physical flows of aluminium from liquid metal to final products.

\subsection{Limits of existing maps of aluminium flow}

The most significant contribution towards mapping aluminium flows comes from a combined industrial effort to create a global dynamic MFA model for aluminium flows and stocks. This original model was created at Alcoa in the late 1990s, then taken over by the Global Aluminium Recycling Committee (GARC), and is now being developed by the International Aluminium Institute. Bruggink and Martchek, ${ }^{10}$ Boin and Bertram (2005) ${ }^{11}$ and Martchek (2006) ${ }^{12}$ have published results from the model and describe its development during this time. The industry also recognized the benefits of reporting clear and transparent aluminium data, with the EAA publishing a 2004 Europe and global flow diagram based on the model ${ }^{13}$ and the International Aluminium Institute publishing an annual MFA diagram in their Aluminium for Future Generations reports (2006-2009), ${ }^{2}$ while also extending the regional coverage of the model.

This dynamic model of aluminium stocks and flows is built around annual primary aluminium production data and net product shipments by market sector, and for ten geographical regions. Scrap flows from casting, forming, and fabrication are estimated based on yield rates for each market sector, and end-of-life scrap from discarded products is estimated based on historical product shipments, product life times, scrap collection rates and melting yields. A full summary of the development of the dynamic MFA model is given by Bertram et al. ${ }^{14}$ and the International Aluminium Institute has recently created an online animated version of the flow diagram. ${ }^{15}$

Chen and Graedel ${ }^{16}$ provide a review of anthropogenic element cycles, listing 26 different material flow analysis (MFA) studies of aluminium across a range of geographical scales and life-cycle stages. Two additional sources were not included in the review, but proved useful for our analysis:

- Liu et al. (2011) ${ }^{5}$ create a dynamic material flow model to simulate aluminium stocks and flows in the U.S. and associated greenhouse gas emissions, and show that although in-use stocks are still growing large mitigation potential existing through recycling.

- AluNorf, the world's largest aluminium rolling and remelting plant, uses the European Commission's Eco-Management and Audit Scheme (EMAS) to report environment indicators for the operation of the plant. EMAS requires the company to disclose their annual material and energy flows, ${ }^{17}$ which they report using a material flow diagram.

Previous studies of aluminium flows are useful for discussion of issues in specific regions, processing routes and products. However, research to date is incomplete, and unsuitable for our purpose of assessing global emissions abatement options, because it is either not at the global scale, or in the case of the few global studies available, does not describe the entire supply chain in sufficient detail. This paper aims to provide a more detailed mapping of global aluminium flows and is motivated by three specific knowledge gaps in the existing MFA modelling literature: 
- As aluminium flows from production (smelting and melting), through intermediate products, to final fabricated goods, the flows divide, becoming smaller and more diverse. A handful of flows might be sufficient to describe the upstream production of aluminium, whereas the downstream fabrication of aluminium products is more diverse and complex. For this reason, a detailed mapping of the links between intermediate products and fabricated goods is missing from the current MFA modelling, but is important if we wish to examine options for material efficiency.

- The global aluminium scrap system has to date only been mapped at an aggregated level, with no separation between the aluminium scrap flows to remelters (which melt scrap for use in wrought products) and to refiners (which melt scrap for use in cast products). Providing a detailed analysis of aluminium scrap flows is important as the value of recycling is undermined when alloy streams are mixed, down-cycled or diluted during melting.

- To create our map of global aluminium flows involves collating and balancing data from many different sources, giving us the opportunity to resolve discrepancies between existing data sets.

\section{Constructing a map of global aluminium flows}

In this section we describe the methodology for allocating aluminium flows and accounting for manufacturing yields using a matrix notation, and the population of the matrices using data from a range of sources, while ensuring a consistent mass balance. The resulting model of aluminium flows is presented visually as a Sankey diagram allowing comparisons to be quickly made between the scale of flows. The Sankey diagram format has been used previously by Cullen and Allwood to map global energy flows ${ }^{18-19}$ and to create an equivalent map of global steel flows. ${ }^{20}$ A preliminary version of the aluminium Sankey diagram was presented in the book, Sustainable Materials: with both eyes open. ${ }^{9, p 55}$ The map for this paper has been revised following further consultation with the International Aluminium Institute and our industrial partners, and cross-referencing to additional data sources. This resulted in substantial changes to many of aluminium flows, particularly for the scrap recycling flows to Remelters and Refiners, and required a complete rebalancing of the model. Furthermore, for the first time we have publish the detailed analysis and source data used to create the diagram in the comprehensive Supporting Information, enabling other research groups to use and build upon this work.

\subsection{Methodology}

The global aluminium supply chain is divided into five major process steps, shown in Table 1, which form the vertical slices of the Sankey diagram. Each slice can contain several individual processes, and represents a transformation of an input aluminium flow into three possible outputs: useful aluminium products; scrap aluminium; losses (typically as dross or oxidised aluminium).

\begin{tabular}{ll} 
Slices & Description \\
\hline Electrolysis/ & $\begin{array}{l}\text { Alumina (extracted from bauxite ore) is converted using electrolysis to liquid aluminium ore. } \\
\text { Melting }\end{array}$ \\
$\begin{array}{l}\text { Aluminium scrap (from forming, fabrication and end-of-life) is melted in remelters (to make } \\
\text { wrought alloys) and refiners (to make casting alloys). }\end{array}$ \\
$\begin{array}{l}\text { Liquid aluminium is cast into slab, billet and alloy ingots, and subsequent remelting and } \\
\text { casting in downstream facilities. }\end{array}$
\end{tabular}


Rolling/

Slab ingots are hot rolled to plate and strip with some material undergoing further cold rolling

Forming/ and foil rolling; billet ingots are extruded or wire drawn; alloy ingots are shape cast to produce Shape Casting a range of intermediate products.

Fabrication Intermediate products are cut, joined, machined and assembled into fabricated products.

End-uses

Fabricated products are allocated to vehicles, industrial equipment, construction and metal products, and then divided further into subcategories.

Table 1-Major processes steps for aluminium are used to create the five vertical slices in the Sankey diagram.

For each of the five slices, we map the inputs (vector $\mathbf{x}$ ) onto the outputs (vector $\mathbf{y}$ ) using two matrices: an allocation matrix $\mathbf{A}$, which maps each input, by fractions, onto each output, and a manufacturing yield matrix $\mathbf{Y}$, which accounts for any material discarded as scrap in transforming the input materials into output products. The two matrices are of equal size and are multiplied element wise, using the Hadamard product (symbol $\circ$ ). Written formally:

$$
\mathbf{y}=(\mathbf{A} \circ \mathbf{Y}) \mathbf{x}
$$

where $y$ is a vector of end-use goods and $x$ is a vector of intermediate products. An equivalent loss vector $\mathbf{y}_{L}$ is defined as:

$$
\mathbf{y}_{L}=(\mathbf{A} \circ(\mathbf{J}-\mathbf{Y})) \mathbf{x}
$$

where $\mathbf{J}$ is a matrix of ones, of equal size to $\mathbf{Y}$ and $\mathbf{A}$.

Four allocation matrices and four yield matrices are created to map the five slices in the Sankey diagram and populated using industrial statistics from a number of different sources. In some cases, the mapping is inferred, estimated or back calculated, if the direct values for the vectors or matrices are not available.

\subsection{Global model of aluminium flows}

In this section we summarise the main data sources, calculations and assumptions behind our global model. The model is balanced to remain consistent with the overview of major global aluminium flows in 2007, provided in the International Aluminium Institute's global mass flow diagram ${ }^{2}$ and supporting dynamic model. ${ }^{3}$ Full details of the data sources and the mapping process are given in the Supporting Information: $§ 2$.

Electrolysis/Melting/Casting: The International Aluminium Institute diagram ${ }^{2}$ shows the sources of liquid aluminium (75.6Mt) divided evenly into primary aluminium (electrolysis) and remelted aluminium (recycled scrap), while the International Aluminium Institute model ${ }^{3}$ gives a breakdown of the scrap inputs for remelting: casting (1.6Mt); internal scrap/forming (20Mt); fabrication (9.5Mt); post-consumer/end-of-life (8.3Mt).

Recycled aluminium is produced in two separate processes: Remelters, which produce wrought alloys ( $<10 \%$ alloy) for rolled and extruded products; Refiners, which produce casting alloys $(<20 \%$ alloy) for shape-cast products and deoxidation aluminium. Each scrap input flow is divided between the Remelter and the Refiner based on a mass balance of scrap flows for Europe, ${ }^{11}$ resulting in all 
casting scrap, $10 \%$ of wrought forming and fabrication scrap, and $78 \%$ of end-of-life scrap being sent to the Refiner.

The liquid aluminium from Electrolysis, Remelters and Refiners is cast into ingots for transportation to downstream production facilities, creating $1.6 \mathrm{Mt}^{3}$ of 'aluminium skimmings' of which $0.8 \mathrm{Mt}$ is recovered as aluminium. Internal casting losses (i.e. defects, sawing, scalping) are not reported by the International Aluminium Institute, but these remelting loops are estimated to add $9 \%$ to the cast output, using the Remelter mass balance from AluNorf. ${ }^{17}$ In many cases ingots are remelted and recast a second time to refine the alloy mix prior to downstream forming/casting processes, although fraction of recast aluminium could not be ascertained.

Scrap recycling requires the addition of primary aluminium to 'sweeten the melt' and obtain the desired alloy mix. The primary sweetner fraction for the Remelter is set at $5 \%$ based on a mass balance from AluNorf ${ }^{17}$ and the observed fraction at a UK remelting facility producing UBC ingots. The sweetner fraction for the Refiner is found by balancing the demand for wrought alloys (46.7Mt) and shape-casting alloys (27.3Mt) against the scrap inputs to the Remelter (16.9Mt) and the Refiner (22.4Mt), after accounting for casting yield losses. ${ }^{3}$ The result is $7.1 \mathrm{Mt}$ of primary sweetner input to the Refiner, equal to $25 \%$ of the Refiner input.

Rolling/Forming/Shape Casting: The demand for Rolling, Extrusion, Wire Drawing and Shape Casting is back calculated from the Intermediate Product vector. The International Aluminium Institute model ${ }^{4}$ lists semi-fabricator yields (corresponding to our forming/casting processes), but these are organized by end-use categories. It is more accurate to estimate the forming/casting yields directly for each process while accounting for the cascading flows between the hot, twin roll, cold and foil rolling processes. Therefore, we survey forming yields from four literature sources-AluNorf, ${ }^{17}$ EAA, ${ }^{21}$ Milford et al.,22 Schifo and Radia ${ }^{23}$ - covering individual processes and multi-process chains, to assign yields to each forming/casting process. These are adjusted in combination with the Forming/Casting allocation matrix to match the total forming/casting scrap of 20Mt from the International Aluminium Institute global diagram. ${ }^{2}$

Fabrication: The International Aluminium Institute model ${ }^{3}$ collates net product shipments (equivalent to Intermediate Products in our model) for the ten major regions covering the world (1950-2007) and estimates fabrication yields to generate a breakdown of "finished products", which are matched to the End-use categories in our model. However, the International Aluminium Institute product shipment data is organised by end-uses (i.e. buildings, transport, machinery) rather than intermediate product categories (i.e. rolled, extruded, shape-cast) required for the Sankey diagram. Therefore, we back-calculate the Intermediate Product vector by using the fabrication yields from the International Aluminium Institute model and creating a fabrication allocation matrix: using sector specific breakdowns from North America ${ }^{24, t a b 13}$ for Construction and Transport end-uses; assuming Mechanical Equipment has a similar breakdown to Cars; using direct one-to-one allocations for Electrical Cable and Drinks Cans; estimating breakdowns for Other Electrical and the remaining Metals Products. Each row of the matrix is finally balanced to match the End-uses vector, while the total fabrication scrap is constrained to match the International Aluminium Institute value of $9.5 \mathrm{Mt}^{2}$ A complete description of the data sources and assumptions is provided in the Supporting Information, §2.7. 


\subsection{Data uncertainty}

Aluminium production statistics are not reported with error bands, as is common for experimental findings, making it impossible to determine data accuracy or perform an uncertainty analysis for our model. Data is normally collated from individual company surveys, which are aggregated at the country, regional or global level and reported in national statistical bodies and by trade organisations. Some likely sources of uncertainty are: misinterpretation of the survey questions and the terminology used to describe process and materials; unintentional or deliberate misreporting of data in the surveys; incomplete coverage of global production facilities, requiring data to be scaled; calculation errors in the aggregation of data; miscommunication of data in published reports. Organisations such as the International Aluminium Institute work to minimise data errors, by crossreferencing data sources and auditing their data collection practices, nevertheless some degree of error is still likely to persist.

In our analysis, we attempt to further minimise data uncertainty by: relying heavily on a few trusted sources, which are then validated against other sources when available; using mass balance checks for every process and slice to ensure mass conservation; publishing a full supporting information that describes in detail the sources and calculations used in our model. Aluminium flows are reported in the paper to the nearest 100,000 tonnes of aluminium as a precaution to avoid any overstatement of the data accuracy. Despite the limitations of using data of unknown accuracy, our whole-system approach is still valid for comparing the relative scale of global aluminium flows and for directing actions towards where the largest gains can be made.

\section{Results}

Figure 2 presents a map of global aluminium flow for 2007, which traces the flow of aluminium from aluminium production (left) through to fabricated products (right). The map is drawn in a Sankey diagram format, such that the width of each horizontal line in the map is proportional to the mass flow of aluminium, with specific flows given in million tonnes (Mt). A vertical black line indicates a major process step in the aluminium supply chain, where the aluminium flow is split into three possible outputs: useful metal (shown in colour); losses, typically dross or aluminium oxide (shown black); and process scrap which loops back to a melting step for recycling (shown in grey). Two 'recasting' processes are shown with dashed vertical black lines to indicate that some aluminium ingots are remelted and cast a second time to adjust the alloy concentrations or to create an ingot shape more suitable for the downstream processes, although the fraction of aluminium that is recast is unknown. 
The map is the first breakdown of global scrap flows through Remelters and Refiners, including calculation of the dilution flows of primary aluminium to the remelting processes. It is also the first study to map intermediate products onto end-use goods in detail and to disaggregate the scrap generation from rolling, extrusion and shape-casting processes.

\section{Electrolysis / Melting}

Casting Rolling / Forming / Casting

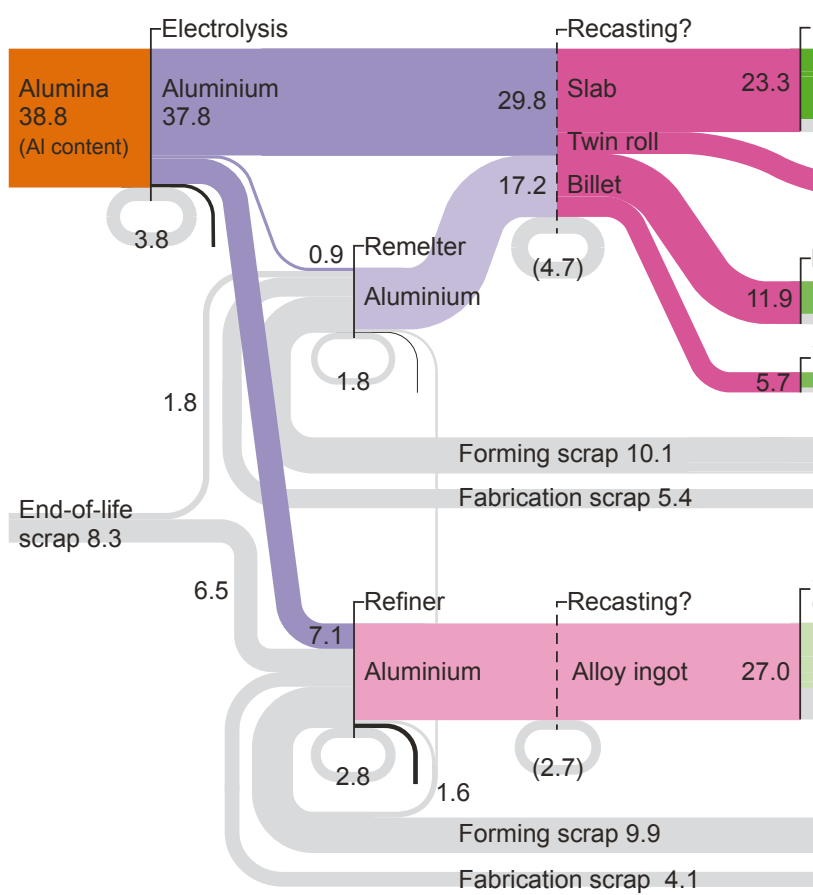
Cold rolling 18.2 18.2

Fabrication

End-use products

Global demand for aluminium products $=45$ million tonnes Hot rolled strip 6.4

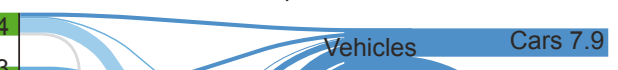
Plate 1.3
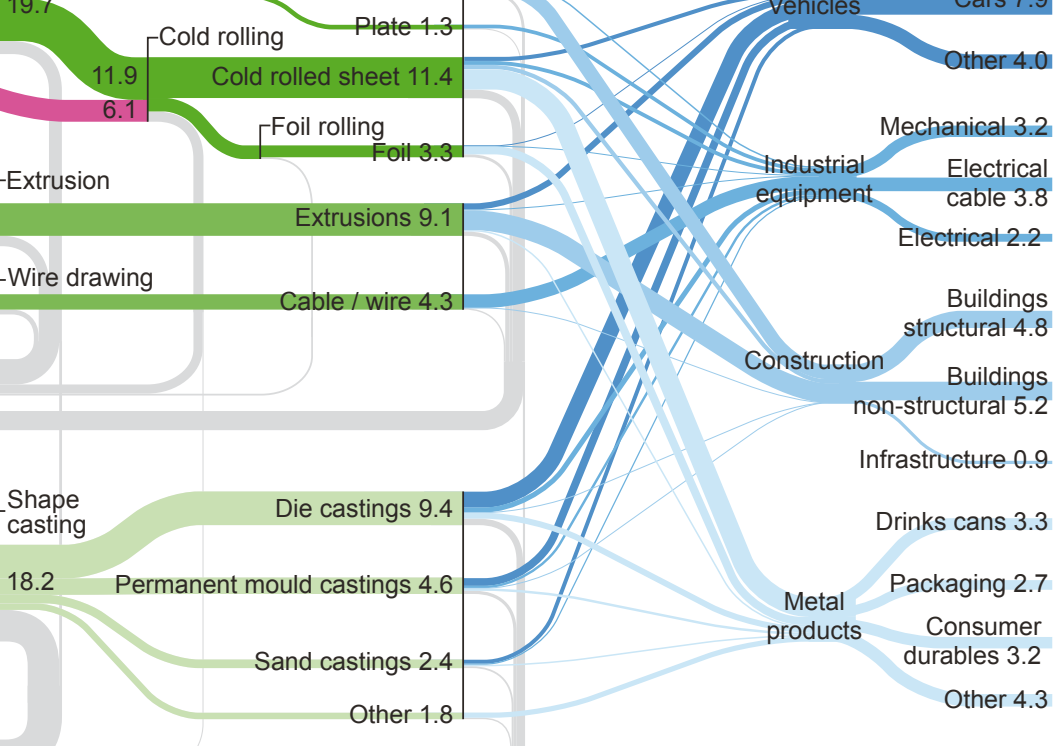

Infrastructure 0.9

Drinks cans 3.3

Figure 2-Sankey diagram, tracing the global flow of aluminium from ore-based and scrap-based production, through casting, forming and fabrication processes, to deliver end-use goods.

\section{Discussion}

Figure 2 shows the relative scale of different aluminium flows in the supply chain. For example, a quick scan of the map shows: roughly half of all aluminium is made from bauxite ore and half from recycled scrap; two-thirds of cast aluminium is formed into wrought products and one-third shapecast; final product demand is divided roughly evenly between vehicles, industrial equipment, construction and metal products. Two additional aspects of the global aluminium map demand further attention: (i) the poor material efficiency of the industry, where approximately $50 \%$ of all cast aluminium is discarded as scrap during manufacturing; (ii) the significant 'dilution' and 'cascade' flows from high grade aluminium to lower purity alloys and the effect on the energy required for recycling. 


\subsection{Material efficiency and industrial scrap}

The material efficiency of the aluminium production system is surprisingly low in comparison to other engineering materials. From a reported $74 \mathrm{Mt}$ of cast aluminium, ${ }^{2}$ the industry delivers only 44.5Mt of final products to consumers-at an average material efficiency (manufacturing yield) of $60 \%$ - with the remaining aluminium discarded as industrial scrap during manufacturing. If we include the unreported internal recycling of casting scrap, the material efficiency falls to $53 \%$ with almost half of all cast aluminium (39.4Mt) discarded as industrial scrap. Furthermore, if we assume that $70 \%$ of all ingots are recast, then the fraction of industrial scrap rises to $50 \%$ of all cast aluminium. In comparison, steel production has an average material efficiency of $76 \% .{ }^{20}$ (Full calculations are included in the Supporting Information, Table S7.)

Certainly, every effort should be made to collect and recycle aluminium scrap, whether the source is manufacturing processes or consumer discards. Current collection efficiencies for industrial scrap are high, so efforts should be focused on end-of-life recycling where collection rates are estimated to range from $50 \%$ in some sectors to as high as $90 \%$ for construction and transport. ${ }^{3}$ (In comparison, steel recycling is reported to average $80 \%,{ }^{25}$ although the exact calculation method may differ.) Yet, of even more importance than recycling is avoiding the generation of scrap at source, through improvements to manufacturing processes, so that recycling of industrial scrap is no longer required.

Analysing the material yields across ingot casting, forming and fabrication processes reveals the reasons behind the high losses of industrial scrap and points to technical options for improving material efficiency.

Ingot casting: The material yield for aluminium ingot casting is $88 \%$ (including internally recycled scrap), much lower than the equivalent for steel of $94 \% .{ }^{20}$ The difference is mainly due to the need to remove inferior quality surface material from ingots (by scalping and sawing) and defects created in the batch casting process, and because the greater material losses can be offset against the typically higher value of aluminium products. The resulting scrap is recycled internally but often not reported in company and industry statistics, and although the overall metal balance is unaffected, the remelting of scrap consumes additional energy.

Almost all aluminium is as some point cast as an ingot, so any improvement in the casting yield has the potential to deliver savings across all products. Electromagnetic casting (EMC) is an alternative ingot casting technology which avoids any contact with a physical mould during casting, providing a smooth cast surface that can normally be rolled without scalping. ${ }^{26}$ Introducing intensive shearing during the melting of aluminium disperses porosity in the melt resulting in considerable reductions in cast defects. ${ }^{27}$ Application of these technologies would increase the material yield of ingot casting from $88 \%$ to an estimated $92 \%$.

Rolling/Forming/Shape-Casting: The overall material efficiency of rolling, forming and shapecasting is $73 \%$, which is well below the yield for steel at $92 \%,{ }^{20}$ with three reasons suggested for the difference. Firstly, a third of all aluminium products are shape-cast compared with only $6 \%$ for steel, and product casting has comparatively lower yields (67\%) than other forming processes $(77 \%$ for aluminium and $90 \%-96 \%$ for steel) due to the complex set of 'runner', 'riser' and 'gating' systems which feed liquid metal into the casting mould. Secondly, one quarter of aluminium products are 
extruded at a comparably low material yield of $76 \%$, whereas extruded steel products are much less common. Thirdly, the average material yield for rolling aluminium is only $75 \%$, compared to $92 \%$ for steel rolling, which can be explained by: the sawing and scalping of slab ingots prior to hot rolling; aluminium being softer than steel and more prone to damage while handling; aluminium being rolled to finer grades and higher surface finishes than steel, resulting in a more quality control defects.

Two key yield improvements are described below, which if implemented would raise the overall material efficiency for forming processes from $73 \%$ to $82 \%$. Firstly, Schifo and Radia ${ }^{23}$ estimate that a 5\% gain in yield can be achieved for aluminium shape-casting, citing improvements to computer solidification modelling and research into the "application of acoustic energy to reduce gating weight and improve casting quality". We assume a similar 5\% improvement is achievable in extrusion and wire drawing processes. Secondly, continuous casting processes, such as twin-roll casting, produce a cast 'sheet' which can be immediately cold-rolled without the need for ingot casting, scalping/sawing and hot rolling. The technology is particularly suited for non-heat treatable alloys and currently onethird of all cold-rolled sheet and foil can be continuously cast. ${ }^{28}$ To calculate the potential savings in industrial scrap, we assume that all cold-rolled sheet and foil is continuously cast, which is equal to two-thirds of all rolled products, noting that $90 \%$ of rolled products are made from non-heat treatable alloys. ${ }^{24}$

Fabrication: The yield for aluminium fabrication processes is $82 \%$, which is only slightly lower than the yield for steel at $85 \%,{ }^{20}$ and is probably due to aluminium components being typically smaller and more complex than steel products. Reducing industrial scrap across all processes is made more difficult by the lower melting temperature of aluminium, at $600^{\circ} \mathrm{C}$ compared to $1600^{\circ} \mathrm{C}$ for steel, which results in lower energy costs for remelting, creating less incentive to reduce aluminium manufacturing scrap. Based on a previous analysis, ${ }^{8}$ we estimate that fabrication yields could be increased up to $90 \%$.

Potential to reduce industrial scrap: The technical options and estimated yield improvements described above represent our best estimate of the practical limits of material efficiency applied to industrial aluminium scrap. We calculate that if all options were applied together, then today's 45Mt of aluminium in end-use goods would require only 65Mt of cast aluminium, avoiding 19Mt of industrial scrap recycling. In practice, a detailed analysis of the economic and institutional barriers would be required to assess the likely adoption of this material efficiency strategy.

\subsection{Is recycling always the best option?}

Recycling is less energy intensive than making aluminium from ore, but recycling is not always as good as it looks. In particular, the practice of dilution and cascading result in significant flows of aluminium from high-grade to lower purity alloys, increasing the energy required for recycling.

Dilution: Our map of global aluminium flows (Figure 2) shows 8.0Mt per year of pure aluminium being used to dilute (or 'sweeten') the alloy mixes in the Remelting and Refining processes.

Thermodynamics dictates that it is easy to add alloys to aluminium but very difficult to remove them, and therefore dilution is mostly irreversible and results in a permanent downgrading of aluminium quality. The practice of dilution also distorts the energy requirement of recycling. 
Table 2 demonstrates that the embodied energy of recycled aluminium increases rapidly when using primary 'sweetner' to dilute the alloy mix. The baseline energy requirements are taken directly from the International Aluminium Institute recycling website, ${ }^{15}$ and matches the claim that "Aluminum recycling requires up to $95 \%$ less energy than primary production" if a direct comparison is made between electrolysis against scrap melting. However, diluting the scrap mix with 5\% pure aluminium sweetner (e.g. as calculated for Remelters) nearly doubles the embodied energy of the recycled aluminium, and the addition of $25 \%$ sweetner (as observed for Refiners) results in a five-fold increase in embodied energy, with aluminium recycling now requiring nearly one-third of the energy of primary production. Furthermore, the collection, sorting and cleaning of recycled scrap, and manufacturing the product for a second time, add even more energy to the equation.

\begin{tabular}{lrrrr}
$\begin{array}{l}\text { Pure Al used } \\
\text { to dilute } \\
\text { scrap (\%) }\end{array}$ & $\begin{array}{r}\text { Eecycling } \\
(\mathrm{GJ} / \mathrm{t})^{\mathrm{a}}\end{array}$ & $\begin{array}{r}\text { Electrolysis } \\
(\mathrm{GJ} / \mathrm{t})^{\mathrm{b}}\end{array}$ & $\begin{array}{r}\text { Total } \\
(\mathrm{GJ} / \mathrm{t})\end{array}$ & $\begin{array}{r}\text { Compared to } \\
\text { electrolysis (\%) }\end{array}$ \\
\hline $\begin{array}{l}\text { Electrolysis (pure Al) } \\
\text { Industry claim (0\%) }\end{array}$ & 0 & 170 & 170 & $100 \%$ \\
Remelter (5\%) & 10 & 0 & 10 & $6 \%$ \\
Refiner (25\%) & 10 & 9 & 19 & $11 \%$ \\
\hline
\end{tabular}

Notes:

a It is assumed that the pure $\mathrm{Al}$ from electrolysis (sweetner) must be remelted using the same energy as required for melting scrap

b Energy embodied in the primary 'sweetner' during primary production of aluminium using electrolysis.

Table 2-The effect of using pure aluminium (sweetner) to dilute scrap , on the embodied energy of recycled aluminium.

The global mass balance requires a dilution flow of pure aluminium to meet the demand for shape cast products, resulting in an average $25 \%$ sweetner fraction for Refiners. The only feasible alternative to balance scrap supply with cast product demand would be a significant increase in the down-cycling of wrought industrial scrap to the Refiner. Such a scenario would contradict the mass balance data from Europe, and would still result in the down-grading of higher quality aluminium and increase the embodied energy of recycled aluminium. The high fraction of pure aluminium sweetner used in Refiners is surprising. It indicates the level of scrap supply constraint that Refiners are forced to operate under, for without the use of pure aluminium, Refiners would be unable to realise the residual value of the recycled scrap.

Down-cycling: Six main alloying metals—copper, magnesium, manganese, silicon, zinc and lithiumare added to wrought alloys in low concentrations and casting alloys in higher concentrations. Nakajima et al. have evaluated the removal limits of alloys and impurities during aluminium scrap melting and concluded that apart from magnesium and zinc, all other alloying elements are almost impossible to remove, even under varying temperature and oxygen partial pressure conditions. ${ }^{29}$ For this reason, wrought alloys can be recycled into casting alloys, but the reverse is practically impossible, so recycling tends to cascade or down-cycle from wrought alloys to less pure shape casting alloys. 
Figure 2 shows the extent of down-cycling in the aluminium industry, which results in an estimated 6.1Mt of wrought scrap being diverted into cast products:

- Only about a fifth of end-of-life scrap is remelted into wrought alloys, despite wrought products outweighing cast production by two to one. We estimate that $3.7 \mathrm{Mt}$ of wrought scrap is downcycled into cast products, assuming product lifetimes for wrought and cast products are the same.

- Industrial scrap can be easily segregated and cleaned, yet we found that $10 \%$ of industrial scrap from forming and fabrication processes (1.7Mt) is still diverted to refiners to make casting alloys.

- Wrought ingot casting losses (skimmings, $0.7 \mathrm{Mt}$ ) are sent for reprocessing to remove impurities, but the recovered aluminium is not returned to Remelters, but instead is cascaded to Refiners.

The recycling system in its current form is only viable because growth in demand for new products outstrips the scrap aluminium available from discarded products, allowing wrought scrap to be downgraded and used in cast products, while primary aluminium is mainly used in wrought products. This behaviour is rational given the current economic drivers in the system, where the scrap supply will cascade to the whomever values the material, irrespective of what is the most optimal solution for material efficiency. However, in future, the recycling path for scrap from cast products may become constrained. Modaresi and Müller ${ }^{30}$ have explored such a scenario for automobiles and show that under business as usual assumptions a surplus of non-recyclable casting scrap will emerge by $2018 \pm 5$ years, while Hatayama et al. ${ }^{31}$ forecast a surplus of $6.1 \mathrm{Mt}$ of unrecyclable scrap in 2030, for Europe, United States, Japan and China, due to decreasing demand for cast alloys resulting from the introduction of electric vehicles. Such projections require a dynamic analysis of aluminium stocks over many years, as the supply and price of recycled aluminium depends critically on the flow of stock products reaching end-of-life, as explained by Blomberg and Soderholm. ${ }^{32}$

Options to minimise dilution and down-cycling: We have identified four possible solutions for addressing the problems of dilution and down-cycling, which will require further research and development to be realised:

- Develop better solutions for segregating and sorting of end-of-life scrap, and promote take-back loyalty schemes for unwanted products, to raise the fraction of wrought aluminium recycled in Remelters. Limiting the number of different alloys in today's products would aid the future separation and recovery of specific alloys.

- Explore options to reuse discarded products, to avoid recycling completely.

- Reduce any potential surplus of casting alloys by developing new shape-cast product applications. Research at the Brunel Centre for Advanced Solidification Technology on grain refinement of as-cast aluminium alloys using physical shear of the alloy melt and enhanced heterogeneous nucleation, is expected to deliver improved mechanical properties for cast products without the need for forming and heat treatment processes. ${ }^{27}$ 
- Develop a better understanding of the demand drivers for cast and wrought products and the future availability of scrap, so future shortfalls or surpluses of specific alloys can be identified and responses formulated to avoid the practice of diluting scrap with pure aluminium.

\subsection{Future work}

In this paper, we have mapped the flow of aluminium from liquid aluminium to final products for the year 2007 and developed a framework for directing actions to improve material efficiency and reduce the environmental impacts of aluminium production. We have identified a genuine need to improve data collection for Remelting and Refining processes, and in particular to ascertain the fraction of aluminium ingots which are recast before forming processes and to confirm the fraction of pure aluminium sweetner used for dilution of the alloy mix.

In future work, it would be possible to include the energy inputs and resulting $\mathrm{CO}_{2}$ emissions in the model, and use dynamic modelling and demand scenarios to predict how the map might change in the future, along with an economic analysis to compare the costs of different strategies. Finally, further work is required to evaluate the impact of economic and institutional barriers on the group of strategies described by material efficiency. 


\section{Acknowledgements}

Both the authors are supported by a Leadership Fellowship provided by the UK Engineering and Physical Sciences Research Council (EPSRC) reference EP/G007217/1. The authors would like to thank Margarita D. Bambach, Daniel R. Cooper, Rachel L. Waugh and Chris Bayliss for their generous contributions to the paper.

\section{Supporting Information Available}

The Supporting Information for this paper describes in detail the assumptions, calculations, and references used to construct the map of global aluminium flows. This material is available free of charge via the Internet at http://pubs.acs.org.

\section{References}

1. Tracking Clean Energy Progress: Energy Technology Perspectives 2012 excerpt as IEA input to the Clean Energy; International Energy Agency, OECD, Paris, France 2012; http://www.iea.org/media/etp/Tracking_Clean_Energy_Progress.pdf/

2. Aluminium for future generations/2008 update; International Aluminium Association: London, 2008; http://www.world-aluminium.org/media/filer/2012/06/12/fl0000286.pdf/

3. Global Aluminium Recycling Committee mass flow model; International Aluminium Association: London, 2011.

4. Energy technology transitions for industry 2009: strategies for the next industrial revolution; International Energy Agency: Paris, 2009; http://www.iea.org/textbase/nppdf/free/2009/industry2009.pdf/

5. Liu, G.; Bangs, C.E; Müller, D.B. Unearthing potentials for decarbonizing the U.S. aluminum cycle. Environ. Sci. Technol. 2011, 45 (22), 9515-22.

6. Luo, Z.; Soria, A. Prospective study of the world aluminium industry; Joint Research Centre, Institute for Prospective Technological Studies, European Communities: Luxembourg, 2008; http://ftp.jrc.es/EURdoc/JR40221.pdf/

7. G8 Hokkaido Toyako summit leaders declaration; Ministry of Foreign Affairs of Japan, July 8, 2008; http://www.mofa.go.jp/policy/economy/summit/2008/doc/doc080714_en.html/

8. Allwood, J. M.; Cullen, J. M.; Milford, R. L. Options for achieving a 50\% cut in industrial carbon emissions by 2050. Environ. Sci. Technol. 2010, 44 (6), 1888-94.

9. Allwood, J. M.; Cullen J. M.; Carruth M. A.; Cooper D. R.; McBrien M.; Milford R. L.; Moynihan M.; Patel A.C.H. Sustainable materials: with both eyes open. UIT: Cambridge, England, 2012; http://www.withbotheyesopen.com/

10. Bruggink, P. R; Martchek, K. J. World-wide recycled aluminum supply and environmental impact model. In, Light Metals and Metal Matrix Composites 2004: Hamilton, Ontario, Canada, 22-25 August 2004.

11. Boin, U.M.J.; Bertram, M. Melting standardized aluminum scrap: A mass balance model for Europe. JOM 2005, 57(8), 26-33.

12. Martchek, K.J. Modelling more sustainable aluminium. Int J LCA 2006, 11(1), pp.34-37. 
13. Global aluminium recycling: a cornerstone of sustainable development; European Aluminium Association: Brussels; International Aluminium Association: London; Organisation of European Aluminium Refiners and Remelters: Dusseldorf, Germany; 2009.

14. Bertram, M.; Martchek, K.J.; Rombach, G. Material flow analysis in the aluminum industry. J Ind Ecol. 2009, 13(5), 650-654.

15. Recycling website; International Aluminium Association: London, 2012, http://recycling.worldaluminium.org/

16. Chen, W.Q.; Graedel, T.E. Anthropogenic cycles of the elements: a critical review. Environ. Sci. Technol. 2012, 46 (16), 8574-86.

17. Environmental Statement 2010. Aluminium Norf GMbH (AluNorf): Neuss, Germany, 2010, http://www.alunorf.com/english/sicherheit_umwelterklaerung.php/

18. Cullen, J. M.; Allwood, J. M. The efficient use of energy: tracing the global flow of energy from fuel to service. Energy Policy 2010, 38 (1), 75-81.

19. Cullen, J. M.; Allwood, J. M. Theoretical efficiency limits for energy conversion devices. Energy 2010, 35 (5), 2059-69.

20. Cullen, J.M.; Allwood J.M.; Bambach M.D. Mapping the global flow of steel: from steelmaking to end-use goods. Environ. Sci. Technol. 2012 (under review).

21. Environmental profile report for the European aluminium industry. European Aluminium Association: Brussels; Organisation of the European Aluminium Recycling Industry: Dusseldof, Germany; 2008. http://www.alueurope.eu/environmental-profile-report/

22. Milford, R. L.; Allwood, J. M.; Cullen, J.M. Assessing the potential of yield improvements, through process scrap reduction, for energy and $\mathrm{CO}_{2}$ abatement in the steel and aluminium sectors. Resour. Conserv. Recy. 2011, 55 (12), 1185-95.

23. Schifo J.F. and Radia J.T. Theoretical/best practice energy use in metalcasting operations; U.S. Department of Energy Industrial Technologies Program: Washington, DC, 2004. http://prod.afsinc.rd.net/files/best\%20practice\%20energy-schifo-radia-may\%202004.pdf/

24. Aluminum Statistical Review for 2008; The Aluminum Association: Arlington, VA, 2008.

25. Fact sheet: steel and raw materials; World Steel Association: Brussels, 2011; http://www.worldsteel.org/dms/internetDocumentList/fact-sheets/Fact-sheet_Rawmaterials2011/document/Fact\%20sheet_Raw\%20materials2011.pdf/

26. Prasso, D.C.; Evans, J.W.; Wilson, I.J. Heat Transport and Solidifcation in the Electromagnetic Casting of Aluminium Alloys: Part I. Experimental Measurements on a Pilot Scale Caster. Metall. Trans B., 1995(26B), 1243-1251

27. Fan, Z.; Wang, Y.; Xia, M.; Arumuganathar S. Enhanced heterogeneous nucleation in AZ91D alloy by intensive melt shearing, Acta Materialia 2009, 57(16) 2009, 4891-4901.

28. Hamer, S.; Romanowski, C.; Taraglio, B. Continuous casting and rolling of aluminum: Analysis of capacities, products ranges and Technology, Light Metal Age 2002, 60, 6-17.

29. Nakajima, K.; Takeda O.; Miki, T.; Matsubae, K.; Nakamura, S.; Nagasaka, T. Thermodynamic analysis of contamination by alloying elements in aluminum recycling. Environ. Sci. Technol. 2010. 44(14), 5594-6000

30. Modaresi, R.; Müller, D.B. The role of automobiles for the future of aluminium recycling. Environ. Sci. Tech. 2012(46), 8587-94. 
31. Hatayama, H.; Daigo, I.; Matsuno, Y.; Adachi, Y. Evolution of aluminum recycling initiated by the introduction of next-generation vehicles and scrap sorting technology. Resour. Conserv. Recy. 2012, 66 (12) 8-14.

32. Blomberg, J.; Soderholm, P. The economics of secondary aluminium supply: an econometric analysis based on European data. Resour. Conserv. Recy. 2009, 53 (8) 455-463. 


\section{Electrolysis \\ Pagefb5iófosmental Science \& Technology}

Alumina

38.8

Aluminium

(All content)

2

3

4

5

6

37.8

7

8 


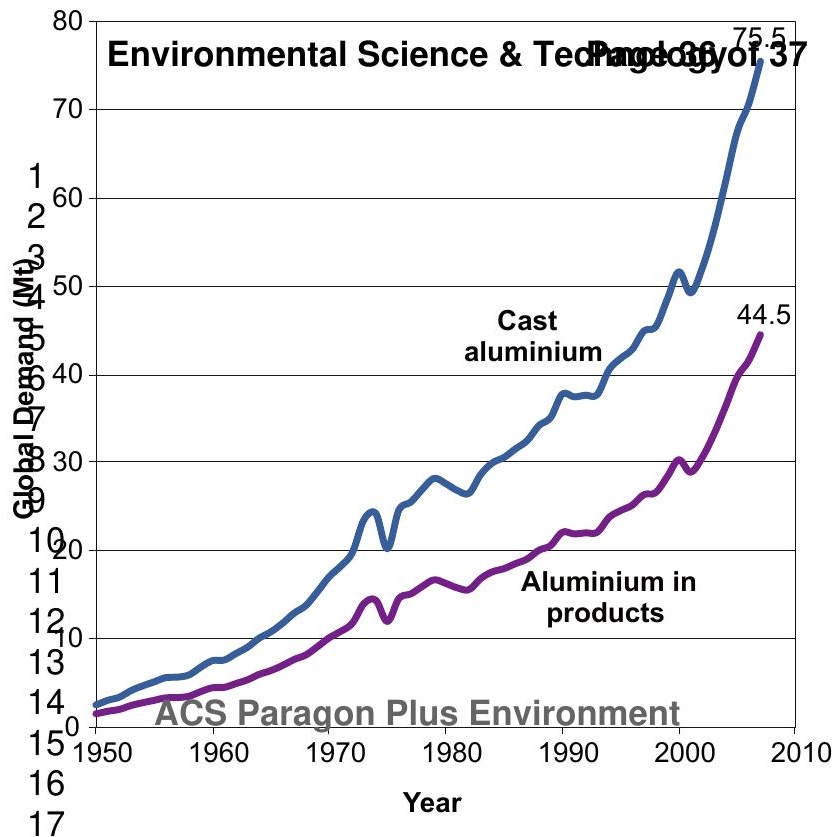




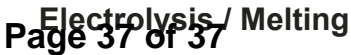

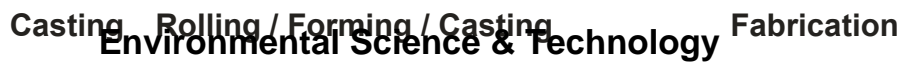

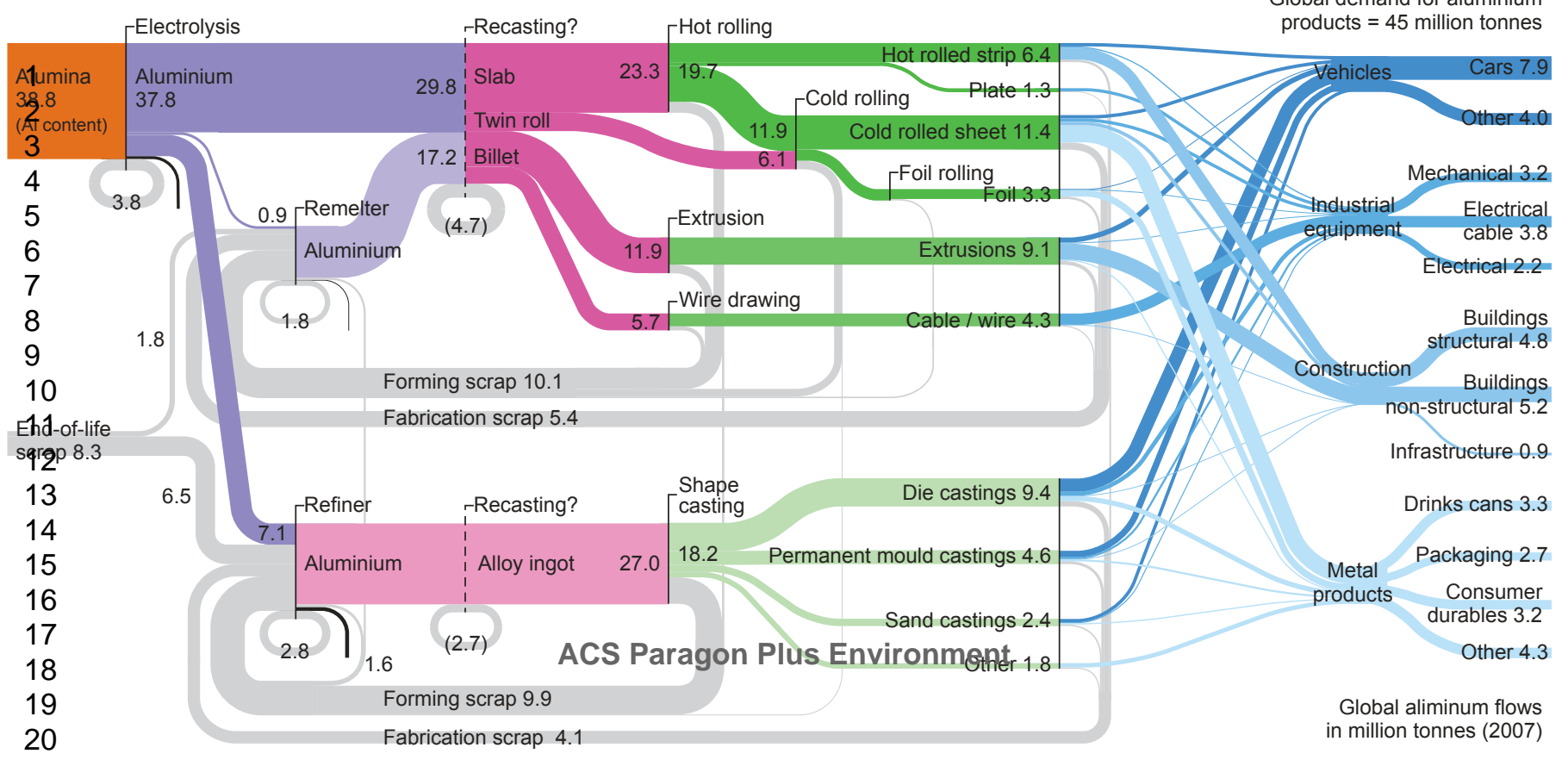

\section{End-uses}

lobal demand for aluminium products $=45$ million tonnes 